\title{
Seismic Behavior Analysis of Long-span Steel - Concrete Composite Arch Bridges
}

\author{
Yang Shanbo ${ }^{1}$ \\ ${ }^{1}$ Hunan City University, Yiyang, Hunan 413000
}

Keywords: sublevel arch bridge; natural vibration characteristics; seismic response; ductile seismic capacity

\begin{abstract}
As a kind of common bridge structure in our country, arch bridge is common in Southwest China, but it is also an area prone to earthquakes in the southwestern area. Therefore, the seismic performance of arch bridge is very demanding. Therefore, based on the simple understanding of the structure and construction characteristics of the steel-concrete composite arch bridge, this paper analyzes the seismic performance of the arch-steel-concrete composite arch bridge in terms of the vibration characteristics, seismic response characteristics, ductile seismic capacity of arch bridge, and seismic performance to provide reference for data information.
\end{abstract}

\section{Introduction}

The arch bridge is the most numerous and most varied among the bridge types. It is also the most common type of bridge on the Chinese highways. In addition, in some areas suitable for building arch bridges, some large-span arch bridges can not only exhibit Beautiful, convenient transportation, but also has some economic significance. In recent years, with the scientific progress of the country, although the arch bridge technology has been comprehensively improved, its seismic performance needs to be further improved to improve the seismic capacity of the arch bridge so as to be applied to more areas [1].

\section{The Long-span Arch Bridge Structure}

At present, there are many types of bridges in the domestic common steel-concrete composite arch bridge, and can generally be divided into a simple system and a combined arch system. One of the most common is the concrete-filled steel tube arch bridge. The concrete-filled steel tube is a kind of composite material. The composite material includes two types of steel and concrete. The concrete-filled steel tube arch bridge enhances the stability of the steel tube wall by using filled concrete. Through the steel sleeve hoop core concrete, in this structure, the core concrete in all three directions are under compression, compressive strength and deformation resistance has been fully improved. The concrete-filled steel tube arch bridge will gradually strengthen its carrying capacity theoretically in the later period, but there are some defects in the concrete-filled steel tube arch bridge, that is, the compactness of the concrete in the pipe is hard to guarantee, which will affect the durability and bearing capacity. At this stage, more than 50 concrete-filled steel tube arch bridges with a span of more than 120 meters have been built domestically, while there are more than 200 concrete arch bridges of more than 200 meters in diameter. Such bridges have great economic advantages when they cross the deep valleys of over 200 meters. In addition, there are reinforced concrete box arch bridge, reinforced skeleton reinforced concrete arch bridge, truss arch bridge, rigid frame arch bridge, different arch bridge between the different forms of construction technology [1].

\section{Steel-concrete Composite Arch Structure and Seismic Performance Analysis}

Arch bridges account for $70 \%$ of the existing national highway bridges, but most arch bridge structures are sensitive to earthquakes, especially lateral and rotational earthquakes and local site 
and traveling wave effects. As a whole, ductility and Seismic performance is relatively poor. Vertical rotation of steel - concrete composite arch bridge is a new type of bridge, we can see from the above, whether it is structural or construction technology, are different from the conventional bridge, with a foundation above the conventional bridge seismic advantages. Taking the design of Pearl River Bridge in Wuchuan, Guizhou for example, the bridge is 152 meters in length and uses the same technique of vertical turning [2]. However, during the construction, a sudden collapse occurred, causing serious economic losses and kidney damage. The main reason for this is that the large-span reinforced concrete faces a greater risk during the construction of the arch rib transfer.[3] However, the steel box and arch ribs of the vertical steel-concrete composite arch bridge can be the factory completed quickly and took the method of sub-lifting, the construction difficulty has been fully reduced, arch ring weight also reduced, the requirements of vertical turning equipment is relatively reduced, thus ensuring the safety and stability of the construction process, the following table is vertical rotation steel - concrete combination arch bridge construction method:

Table 1 vertical steel-concrete composite arch bridge construction methods

\begin{tabular}{|l|l|l|}
\hline $\begin{array}{l}\text { Vertical steel-concrete } \\
\text { composite arch bridge }\end{array}$ & Environmental conditions used & conditions span \\
\hline $\begin{array}{l}\text { Using the crane } \\
\text { vertical construction } \\
\text { method. }\end{array}$ & $\begin{array}{l}\text { For environmental protection and construction } \\
\text { site requirements, it is necessary to have the } \\
\text { transportation construction of heavy crane, } \\
\text { which is suitable for the construction of Bridges } \\
\text { in cities. }\end{array}$ & $30 \mathrm{~m}<\mathrm{L}<50 \mathrm{~m}$ \\
\hline $\begin{array}{l}\text { Cable fastening and } \\
\text { anchoring vertical } \\
\text { construction method. }\end{array}$ & $\begin{array}{l}\text { The requirements for environmental protection } \\
\text { and construction site are relatively high, but the } \\
\text { requirements for traffic conditions are low, and } \\
\text { the vertical construction can be carried out with } \\
\text { the help of the terrain, which can be found in } \\
\text { valleys, mountain areas, rivers and other } \\
\text { Bridges. }\end{array}$ & $30 \mathrm{~L}<80 \mathrm{~m}$ \\
\hline $\begin{array}{l}\text { he construction } \\
\text { method of cable } \\
\text { section horizontal } \\
\text { lifting. }\end{array}$ & $\begin{array}{l}\text { The requirement of construction site is small, } \\
\text { only need to ensure the terrain development is } \\
\text { flat, common in the terrain area construction. }\end{array}$ & $80 \mathrm{~m}<\mathrm{L}$ \\
\hline
\end{tabular}

Steel-concrete composite arch bridge in the design concept of the process, we must take full account of the following elements: the structure of the force, the construction process, the cost of the measure, construction safety, construction period. The first is the structure of the force in the conventional rib arch in the structure of the force will change with the construction and development, and each construction process arch rib force and the bridge compared to there is a big difference, but for Vertical steel-concrete composite arch bridge, in the process of construction, the arch rib to compressive, and the arch after the bridge into the same stress state, the transfer system is relatively less stress, compared with the conventional rib arch, the stability Higher. Then the construction process, the conventional construction methods of long-span arch bridge there are some deficiencies, the most significant of which is the construction process is more complex, the technical difficulty is relatively large [4]. However, the vertical rotation of steel-concrete composite arch bridge innovation proposed a method of construction by the vertical rotation of the composite arch bridge steel arch ribs can be quickly manufactured in the factory segment, and the use of vertical double-rib closed approach, engineering Smaller quantities, simpler process procedures, can be completed in one day, even at high risk swivel collapses, and the risk period is significantly reduced. Thus we can see that the vertical steel-concrete composite arch bridge has the construction period is short, high safety, simple and convenient. Second is the seismic performance of the bridge, ductility and seismic capacity is an important reference for modern bridges, the material performance, the seismic capacity of steel is the strongest of all materials, followed by reinforced 
concrete, while in the structural form, the beam The seismic resistance of the system bridge is stronger and easier to reinforce and repaired after the earthquake. In the vertical arch-steel-concrete composite arch bridge, more steel is used on the main arch, and in the arch area and the dome and the area respectively The steel box filled with concrete cross-section and steel top of the concrete pouring section of the form, effectively improving the ductility and seismic performance. Finally, the project construction, vertical rotation of steel - concrete composite arch bridge in the construction process requires relatively small formwork and brackets, so do not need some of the more expensive lifting equipment and measures to reduce construction costs, and vertical rotation itself The required time is short, can significantly shorten the construction cycle, improve work efficiency, can save $15 \%$ of the total cost. [4]

\section{The Seismic Vibration Characteristics Analysis of Steel-concrete Composite Arch Bridge}

\subsection{Dynamic characteristics of steel-concrete composite arch bridge}

Vertical steel-concrete composite arch bridge also belongs to the new bridge type, although in recent years, has been widely used, but compared with developed countries, there is still a gap in the study of vertical steel-concrete composite arch bridge in our country, the dynamic characteristics mainly include the natural frequency, mode shape and damping ratio of the bridge span structure and the dynamic response of the bridge under the relevant dynamic load. Among them, the natural vibration characteristic is the core reference parameter of the dynamic characteristics of the bridge. The natural vibration characteristic utilizes the natural stiffness index of the bridge in terms of natural frequency, mode shape and damping ratio. The research of dynamic characteristics in vertical steel-concrete composite arch bridge is particularly important. Only by strengthening the study of dynamic characteristics can we reduce the damage caused by earthquakes to the bridge structure as much as possible. In practical application, there are several dynamic loads that the bridge can bear, including vehicles and crowd loads; wind and water flow and explosions Wave force; Seismic force. Among them, the most common method of natural vibration analysis is the finite element method. By analyzing the vibration characteristics of the arch bridge, the dynamic characteristics of the arch bridge can be accurately understood [5].

\subsection{Self-vibration characteristics of steel-concrete composite arch bridge}

Taking algae crossing bridge as an example, this paper analyzes the natural vibration characteristics of vertical steel-concrete composite arch bridge. Firstly, the numerical integral method is used to calculate the natural frequency and vibration mode of the bridge structure. The formulas are as follows:

$$
K \varphi-\omega^{2} M \varphi=0 \text { or }\left(K-\omega^{2} M\right) \varphi=0
$$

Where $\omega$ represents the natural frequency, $\varphi$ belongs to the mode shape, and $\mathrm{K}, \mathrm{M}$ represent the stiffness matrix and the mass matrix, respectively. Then the finite element model of algae crossing bridge was established by using computer finite element software Midas. In the process of modeling, the beam, arch column, capping beam and inter-arch beam were simulated by beam element. By using this software and subspace Iterative method, the bridge modal analysis, obtained in different directions of the bridge structure, the vibration of different parts of the structure map. The conclusion is that there are three main types of vibration in algae crossing bridge: the out-of-plane vibration, the in-plane vibration and the space torsional vibration. With the increase of the mode shapes, the mode shapes are relatively complex, During the calculation, it is found that the algae crossing bridge belongs to the middle rigid structure, and the integrity is strong. The stiffness outside the plane is higher than the in-plane stiffness. It can be seen that the transverse plane is stable and has a large torsional stiffness [5]. By examining the natural vibration characteristics of the bridge, not only the seismic characteristics of the bridge can be judged, but also the existence of the disease in the existing structure can be inversely deduced, and the location of the presumed disease and the influence on the structural safety can be judged. Therefore, in calculating the natural 
vibration characteristics of the bridge, it is necessary to ensure the accuracy of the model, and to adopt the actual measured values in terms of structural parameters and locations to ensure that the natural frequency and mode of vibration are accurate. [3]

\section{The Ductile Seismic Capacity of Steel-concrete Composite Arch Bridge}

\subsection{Harm caused by the earthquake on the bridge}

Earthquakes can cause a lot of damage to the bridge, and its forms are diverse. The common forms of damage can be divided into two types: direct damage and secondary damage. In the direct failure, it can be further divided into bridge damage caused by vertical and horizontal earthquake and damage to the lower part of the bridge structure. In the process of earthquake, the superstructure can be generally avoided to be destroyed, but the damage between the lower structure and the relevant connecting section is obvious, often collapse of the bridge collapse. Secondary damage is common in complex mountain areas, where bridges in the area can be damaged by rockfalls, landslides and dammed lakes, causing the bridges to collapse [5].

\subsection{Seismic response of two types of arch bridges and their comparison analysis}

Before comparing and analyzing the seismic responses of the two kinds of arch bridges, we first calculate the displacements at different cross sections of DX, DY and DZ and compare them with those of conventional reinforced concrete rib arch bridges. Among them, in the case of earthquake intensity $=$ VII degree, the displacements of the arch, left half span 1/4 section and right half section $1 / 4$ section in the DX displacement of the steel-concrete composite arch bridge are respectively $0.002 \mathrm{~mm}$ and $0.0035 \mathrm{~mm}, 0.003 \mathrm{~mm}$, while in the DY displacement, the displacements of the arch, the left half span $1 / 4$ section and the right half section $1 / 4$ section are respectively $0.004 \mathrm{~mm}$, $0.0025 \mathrm{~mm}, 0.003 \mathrm{~mm}$, DZ dome, $1 / 4$ section, the right half of the cross-section of the displacement of $1 / 4$ were: $0.025 \mathrm{~mm}, 0.02 \mathrm{~mm}, 0.016 \mathrm{~mm}$. When the seismic intensity is VII degree, the deformation of the steel-concrete composite arch bridge is larger than that of the conventional reinforced concrete rib arch bridge. In addition, the displacements at different cross sections of DX, DY and DZ under the conditions of earthquake intensity = VIII and IX are also calculated. After comparison, it is found that the deformation of the main arch of the steel-concrete composite arch bridge is larger than that of the conventional reinforced silicon Rib arch bridge [6].

Through the comparative analysis of the relevant experiments, it is found that the main arch rib still maintains its normal working condition under the conditions of VI, VII and VIII degrees of seismic intensity of the arch-bridge with steel-concrete composite arch. However, under the IX seismic load, Plate does not appear serious damage phenomenon, the steel box itself has a greater stress surplus and deformation capacity, can work, will not collapse. At this time, the main arch ribs of the conventional reinforced concrete rib arch bridge can not withstand the load of the earthquake when the intensity of the earthquake is VIII degree, and large-scale damage and cracking begin to occur and the carrying capacity seriously decreases. In addition, through the seismic intensity VII, VIII degree of the case, the main arch ribs of the various sections of the displacement has changed, but the steel-concrete composite arch bridge because of the smaller main arch, so the deformation of the section is greater than the conventional reinforced concrete rib Arch bridge, but its bearing capacity is significantly higher than the conventional reinforced concrete rib arch bridge, and in the seismic IX degrees, the deformation of the main arch of the steel-concrete composite arch bridge is less than the conventional reinforced concrete rib arch bridge, the most important is that the steelThe maximum displacement of the combined construction of the arch bridge is 1.65 times that of ordinary reinforced concrete components. It can be seen that the main arch of the steel-concrete composite arch bridge is more resistant to deformation and more load-bearing capacity, mainly because the steel-concrete composite arch bridge can be combined with different combinations to give full play to the advantages of steel and concrete The steel-concrete composite arch bridge is obviously superior to the conventional reinforced concrete ribbed arch bridge whether it is static load capacity, anti-deformation ability or ductile seismic capacity.[6] 


\section{Conclusion}

In summary, the arch bridge is common in the southwest of the country, because of its relatively good geological conditions, rock integrity and rock depth are more suitable for the construction of arch bridge. In the different construction methods of arch bridge, the steel-concrete composite arch bridge is the most common, but its seismic performance needs to be further improved. Based on the existing construction technology, a new construction method, a computer model, and an appropriate combination of components are adopted to effectively improve the overall bearing capacity and deformation resistance of the arch bridge.

\section{References}

[1] Wang Lei. The bearing capacity of steel-concrete composite arch bridge seismic performance [D]. Chongqing Jiaotong University, 2008

[2] Wu Yibo. Design and study of long-span railway reinforced concrete box arch bridge [D]. Southwest Jiaotong University, 2013

[3] Dong Xiao. Research on the Shock Absorption Control of Long-span Upper-deck Reinforced Concrete Arch Bridges [D]. Lanzhou Jiaotong University, 2011

[4] Zhang Bo. Seismic response analysis of on-site CFST arch bridge considering the interaction between foundation and structure [D]. Shandong University, 2009

[5] Wang Wei. Seismic behavior analysis of long-span CFST arch bridge [J]. Journal of Urban Construction Theory, 2014 (14)

[6] Zhao Heqing, Xu Liang, Yang Huilin, Liu Shizhong. Stability Analysis of Long-span Sheeting CFST Arch Bridges [J]. Journal of Highway and Transportation Research and Development, 2006,23 (11): 82-85 